\title{
Synthesis and in vitro antibacterial activity of new meropenem analogs
}

\author{
Mohammed I El-Gamal ${ }^{1,2}$, Seong Jong $\mathrm{Kim}^{1}$ and Chang-Hyun $\mathrm{Oh}^{1,2}$
}

The Journal of Antibiotics (2011) 64, 687-688; doi:10.1038/ja.2011.70; published online 3 August 2011

Keywords: antibacterial activity; imipenem; meropenem; methoxyimino

Carbapenems are one of the most potent types of antibacterial agents and are among those used as a last resort against infections in the clinical field. Recently, they have been classified into three classes according to their chemical structures. According to this classification, meropenem belongs to $1 \beta$-methylcarbapenems containing (3S)pyrrolidine-3-ylthio moiety. ${ }^{1}$ The $1 \beta$-methyl group slows renal hydrolysis by dehydropeptidase-I (DHP-I) and allows usage as a single agent. ${ }^{2,3}$ Carbapenems with (3S)-pyrrolidine-3-ylthio moiety are reported for their broad-spectrum and potent antibacterial activity. ${ }^{4}$

In the present investigation, we report the synthesis and in vitro antibacterial evaluation of three new meropenem analogs against 18 bacterial strains. Our target is to discover new carbapenem derivatives with improved antibacterial activity (Figure 1).

Our general synthetic route leading to new carbapenem derivatives involved the preparation of appropriately protected thiols containing pyrrolidine ring as a side chain and coupling reaction with the carbapenem diphenylphosphate, followed by deprotection of the resulting protected carbapenems in a usual manner.

The carboxylic acid $\mathbf{1}$ was treated with ethyl chloroformate and diazomethane to give the diazo compound $2 .{ }^{5,6}$ Interaction of 2 with hydrobromic acid afforded the $\alpha$-bromoacetyl derivative $3 .^{5}$ Nucleophilic substitution of the bromo group of 3 with dimethylamino moiety was carried out using dimethylammonium chloride in the presence of triethylamine to give 4. Formation of the methoxyimino

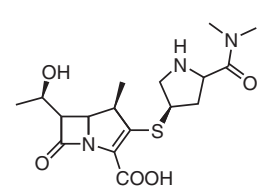

Meropenem la: $\mathrm{X}=\mathrm{N} \sim \mathrm{OCH} 3$

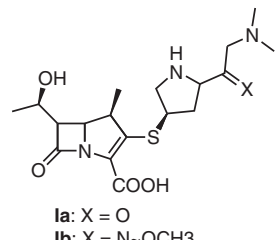

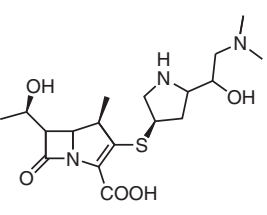

Ic
Figure 1 Structures of meropenem and the target compounds la-c. compound $\mathbf{5}$ was successfully performed by refluxing the carbonyl compound 4 with $\mathrm{N}$-methoxymethanamine hydrochloride in pyridine. Reduction of the carbonyl group of $\mathbf{4}$ using sodium borohydride afforded the corresponding hydroxyl compound 6. Deprotection of the trityl group to mercaptans 7-9 was achieved by treatment of 4-6 with trifluoroacetic acid in the presence of triethylsilane (Scheme 1).

Reaction of the diphenylphosphate derivative $10^{2}$ with the thiols 7-9 in the presence of diisopropylamine yielded the corresponding 2-substituted carbapenems 11a-c. Deprotection of these compounds by treatment with tetrakis(triphenylphosphine)palladium (0) and tributyltin hydride gave the target compounds Ia-c (Scheme 2).

The final products were purified by column chromatography and their purities $(>95 \%)$ were determined by HPLC. Their structures were confirmed by ${ }^{1} \mathrm{H}-\mathrm{NMR}$ and LC-MS.

MIC values were determined by the agar dilution method using test agar. An overnight culture of bacteria in tryptosoy broth was diluted to about $10^{6}$ cells per $\mathrm{ml}$ with the same broth, and inoculated with an inoculation device onto agar containing serial two-fold dilutions of the test compounds. The organisms were incubated at $37^{\circ} \mathrm{C}$ for 18-20 h. The MICs of the test compounds were defined as the lowest concentration that visibly inhibited growth.

The in vitro antibacterial activities of the new meropenem analogs Ia-c against Gram-negative and Gram-positive bacteria are listed in Table 1. For comparison, the MIC values of imipenem and meropenem are also listed. Compounds Ia, $\mathbf{b}$ displayed superior or similar activities against Gram-positive bacteria to meropenem, and against Gram-negative bacteria except Pseudomonas aeruginosa 5455 and imipenem-resistant Acinetobacter baumannii to imipenem. Compound $\mathbf{I b}$ showed higher or similar activity against Gram-positive bacteria to imipenem also. Of special interest, compound Ia showed better or similar activity against third generation cephalosporinsresistant Enterobacter cloacae and Serratia marcescens and imipenemresistant Pseudomonas aeruginosa to both imipenem and meropenem.

${ }^{1}$ Biomaterials Center, Korea Institute of Science and Technology, Seoul, Republic of Korea and ${ }^{2}$ Department of Biomolecular Science, University of Science and Technology, Daejeon, Republic of Korea

Correspondence: Dr C-H Oh, Biomaterials Center, Korea Institute of Science and Technology, PO Box 131, Cheongryang, Seoul 130-650, Republic of Korea.

E-mail: choh@kist.re.kr

Received 9 February 2011; revised 31 May 2011; accepted 20 June 2011; published online 3 August 2011 


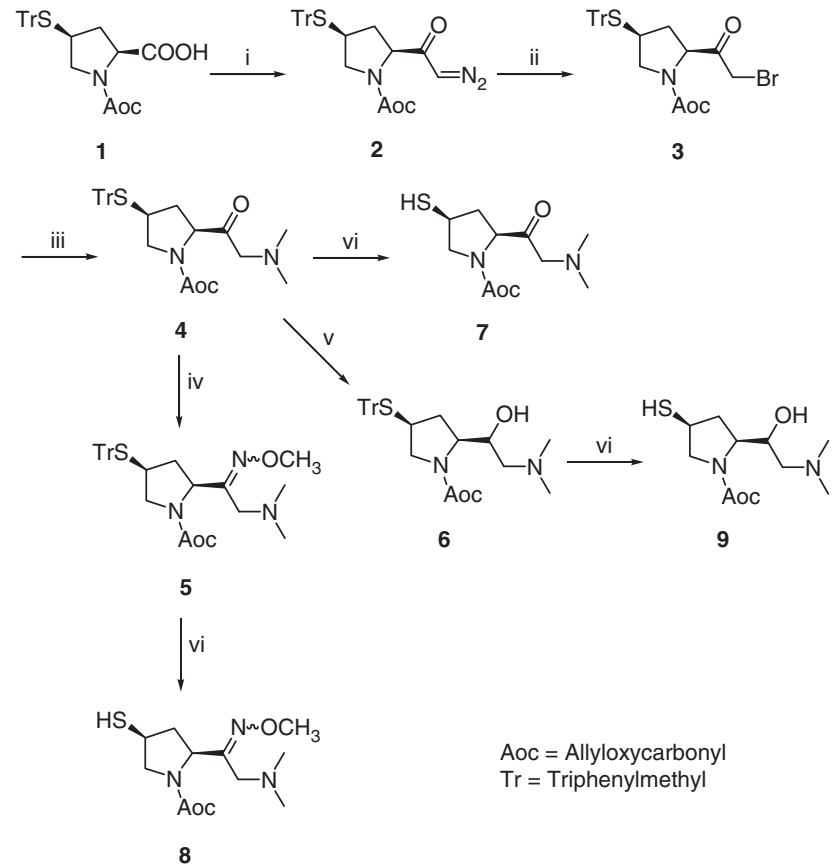

Scheme 1 Reagents and conditions: (i) $\mathrm{ClCOOC}_{2} \mathrm{H}_{5}, \mathrm{CH}_{2} \mathrm{~N}_{2}, \mathrm{THF}$, $-20 \sim-30^{\circ} \mathrm{C}$ then rt, $4 \mathrm{~h}$; (ii) $\mathrm{HBr}$, THF, $-10^{\circ} \mathrm{C}, 4 \mathrm{~h}$; (iii) $\left(\mathrm{CH}_{3}\right)_{2} \mathrm{NH} . \mathrm{HCl}$ (4 eq.), TEA (8 eq.), $\mathrm{CH}_{3} \mathrm{CN}$, rt, $2 \mathrm{~h}$; (iv) $\mathrm{CH}_{3} \mathrm{NHOCH}_{3} . \mathrm{HCl}$ (1.2 eq.), $\mathrm{C}_{5} \mathrm{H}_{5} \mathrm{~N}$, reflux, $8 \mathrm{~h}$; (v) $\mathrm{NaBH}_{4}$ (1 eq.), THF, $0^{\circ} \mathrm{C}, 8 \mathrm{~h}$; (vi) trifluoroacetic acid, triethylsilane, dry $\mathrm{CH}_{2} \mathrm{Cl}_{2}, \mathrm{rt}, 2 \mathrm{~h}$.

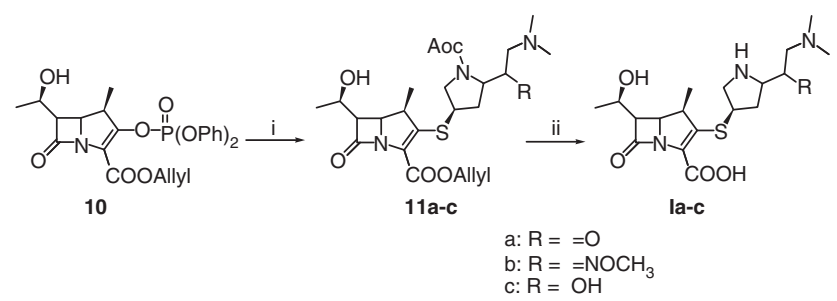

Scheme 2 Reagents and conditions: (i) 7-9, diisopropylethylamine, $\mathrm{CH}_{3} \mathrm{CN}$, $5 \mathrm{~h}$; (ii) tetrakis(triphenylphosphine)palladium (0), tributyltin hydride, dry $\mathrm{CH}_{2} \mathrm{Cl}_{2}, 0{ }^{\circ} \mathrm{C}, 1 \mathrm{~h}$.

The hydroxyl compound Ic showed the lowest activity compared with Ia, b bearing carbonyl and methoxyimino moieties, respectively, and meropenem and imipenem. This suggests that hydroxyl group is unfavorable for antibacterial activity of these compounds.

Upon comparing the activity of the carbonyl compound Ia with that of the methoxyimino derivative $\mathbf{I b}$, compound Ia was more active against Gram-negative bacteria. On the contrary, compound Ib showed higher activity against Gram-positive bacteria. From these
Table 1 In vitro antibacterial activity (MIC, $\mu \mathrm{g} \mathrm{ml}^{-1}$ ) of the meropenem analogues la-c

\begin{tabular}{|c|c|c|c|c|c|}
\hline Strain & la & lb & Ic & IPM $^{\mathrm{a}}$ & MPM $^{b}$ \\
\hline Escherichia coli 04 & 0.013 & 0.049 & 0.391 & 0.195 & 0.025 \\
\hline Klebsiella pneumonia 523 & 0.049 & 0.098 & 0.781 & 0.781 & 0.049 \\
\hline Citrobacter freundii 323 & 0.025 & 0.049 & 0.391 & 0.391 & 0.025 \\
\hline Enterobacter cloacae $34 R^{c}$ & 0.391 & 1.563 & 25 & 1.563 & 0.391 \\
\hline Enterobacter cloacae 34 & 0.049 & 0.049 & 0.391 & 0.781 & 0.025 \\
\hline Serratia marcescens $3349 R^{c}$ & 3.125 & 25 & $>100$ & 3.125 & 6.25 \\
\hline Serratia marcescens 3349 & 0.049 & 0.098 & 1.563 & 0.391 & 0.049 \\
\hline Acinetobacter baumannii 2289 & 12.5 & 6.25 & $>100$ & 12.5 & 6.25 \\
\hline Acinetobacter baumannii $2289 R^{\mathrm{d}}$ & 25 & 25 & $>100$ & 12.5 & 25 \\
\hline Pseudomonas aeruginosa $5455 R^{\mathrm{d}}$ & 12.5 & 50 & $>100$ & 25 & 12.5 \\
\hline Pseudomonas aeruginosa 5455 & 3.125 & 50 & $>100$ & 0.391 & 6.25 \\
\hline Haemophilus influenza 1210 & 3.125 & 3.125 & 25 & 6.25 & 3.125 \\
\hline Satphylococcus aureus 1218 & 6.25 & 0.781 & 25 & 0.781 & 6.25 \\
\hline Coagulase negative staphylococci & 0.195 & 0.049 & 0.391 & 0.025 & 0.098 \\
\hline Enterococcus faecalis 2347 & 6.25 & 1.563 & 25 & 1.563 & 12.5 \\
\hline Streptococcus pneumonia 0025 & 0.007 & 0.004 & 0.025 & 0.007 & 6.25 \\
\hline Streptococcus pyogenes 9889 & 0.007 & 0.004 & 0.025 & 0.004 & 0.007 \\
\hline Streptococcus agalactiae 32 & 0.025 & 0.007 & 0.098 & 0.013 & 0.049 \\
\hline
\end{tabular}

\section{almipenem.}

${ }^{\mathrm{b}}$ Meropenem.

'Third-generation cephalosporins resistant.

dImipenem resistant.

results, it can be concluded that carbonyl group is favorable for activity against Gram-negative bacteria. On the other hand, methoxyimino moiety is more favorable for Gram-positive bacterial inhibition.

\section{ACKNOWLEDGEMENTS}

We would like to thank Korea Institute of Science and Technology (KIST) and Hawon Pharmaceuticals for financial support.

1 El-Gamal, M. I. \& Oh, C.- H. Current status of carbapenem antibiotics. Curr. Top. Med. Chem. 10, 1882-1897 (2010).

2 Shin, D. H., Baker, F., Cama, L. \& Christensen, B. G. Synthetic carbapenem antibiotics.

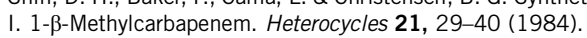

3 Sundelof, J. G. et al. Pharmacokinetics of L-749,345, a long-acting carbapenem antibiotic, in primates. Antimicrob. Agents Chemother. 41, 1743-1748 (1997).

4 Sato, M. et al. Modification of the cysteamine side chain of thienamycin. III. J. Antibiot. 40, 1292-1302 (1987).

5 Cho, J.- H., Ahn, S.- H., Jeon, H., Kim, S. H. \& Oh, C.- H. Synthesis and antibacterial activity of 1B-methyl-2-[5-(1,2-disubstituted ethyl)pyrrolidin-3-ylthio]carbapenem derivatives. Bull. Korean Chem. Soc. 27, 705-712 (2006).

$6 \mathrm{Kim}, \mathrm{J}$ - W. et al. Synthesis and antibacterial activity of $1 \beta$-methyl-2-[5-( $\alpha, \beta$-disubstituted ethyl)pyrrolidin-3-ylthio]carbapenem derivatives. Part II. Bull. Korean Chem. Soc. 27, 1164-1170 (2006). 